\title{
CONSTRUÇÃO E VALIDAÇÃO DE CONTEÚDO DE UMA ESCALA DE PERCEPÇÃO, POR PROFESSORES, DOS COMPORTAMENTOS AGRESSIVOS DE CRIANÇAS NA ESCOLA
}

\author{
Carolina Saraiva de Macedo Lisboa* \\ Sílvia Helena Koller
}

\begin{abstract}
RESUMO. Este estudo visa descrever a construção e a validação do conteúdo de uma escala de percepção, por professores, dos comportamentos agressivos de crianças na escola. Aspectos relacionados à direção da emissão dos comportamentos agressivos foram considerados, focalizando agressão dirigida para o(a) professor(a), para os(as) colegas ou para um âmbito geral. Vinte e oito itens foram elaborados, com base na literatura recente sobre agressividade e desenvolvimento infantil, e avaliados por quarenta juízes (vinte professores de Ensino Fundamental e vinte psicólogos especialistas em desenvolvimento humano). Os juízes indicaram a pertinência do item ao constructo teórico e à direção da agressão. A versão final da escala apresenta 41 itens, sendo 22 mantidos da primeira versão, quatro (4) itens novos, acrescidos segundo a sugestão dos juízes durante a validação de conteúdo, e quinze (15) novos itens, que abordam comportamentos positivos de crianças na escola. A escala pode ser utilizada com o objetivo de pesquisa científica, para avaliar a percepção de professores de Ensino Fundamental sobre o comportamento agressivo de crianças na escola. Novos estudos devem ser realizados para acumular outras evidências sobre a escala.
\end{abstract}

Palavras-chave: agressividade, avaliação psicológica, crianças.

\section{CONSTRUCTION AND CONTENT'S VALIDATION OF THE TEACHER' S PERCEPTDN SCALE OF SCHOOL CHILDREN AGGRESSIVE BEHAVIOR}

\begin{abstract}
The process of construction and content's validation of the Teacher's Perception Scale of School Children Aggressive Behavior is described. The agressive behavior direction (toward teachers, peers, or in general) is considered. Twenty-eight items were built based on literature, and evaluated by 40 judges, who indicated the adequacy of each item. The final version presents 41 items, 22 items about aggressive behavior, 15 items about positive, four new items suggested. The scale may be used for scientific research purpose, to evaluate the perception of elementary school teachers about school children aggressive behaviors. Other validation procedures are suggested.
\end{abstract}

Key words: aggressive behavior, psychological assessment, children.

Este estudo descreve o processo de construção e validação de conteúdo de uma escala de percepção, por professores, dos comportamentos agressivos de crianças na escola. Este instrumento foi construído com base na literatura recente sobre agressividade infantil, abordando as causas e as consequiências deste comportamento e a sua influência no desenvolvimento e na adaptação de crianças (Bandura \& Walters, 1959; Coie \& Dodge, 1998; Ladd \& Burgees, 1999; Ladd \& Profilet, 1996; Rubin, Coplan, Nelson, Cheah \&

Psicóloga, foi bolsista PET/CAPES durante a Graduação na PUCRS, atualmente é Mestranda em Psicologia do Desenvolvimento do Curso de Pós-Graduação em Psicologia do Desenvolvimento da Universidade Federal do Rio Grande do Sul. Membro do Centro de Estudos Psicológicos sobre Meninos e Meninas de Rua (CEP-RUA/UFRGS). Coordenadora do Núcleo de Estudos sobre Desenvolvimento Comunitário e Cidadania (NEDECC), do Programa de Intervenção em Sexualidade, Agressividade, AIDS e Drogas (PISAD) e da Equipe de Pesquisa sobre Violência Doméstica, Agressividade e Coping do CEP-RUA/UFRGS.

\# Psicóloga, Doutora em Educação (PUCRS), Pesquisadora do CNPq e Professora do Curso de Pós-Graduação em Psicologia do Desenvolvimento da Universidade Federal do Rio Grande do Sul. Coordenadora do Centro de Estudos Psicológicos sobre Meninos e Meninas de Rua (CEP-RUA/UFRGS).

Endereço para correspondência: CEP-RUA/UFRGS, Instituto de Psicologia. Rua Ramiro Barcelos 2600/104, Porto Alegre, RS. CEP - 90035-003. Fone: (0xx51) 3165150, Fax: (0xx51) 3304797. E-mail: CEP_RUA@ vortex.ufrgs.br 
Lagace-Seguin, 1999; McWhiter, 1999; Nagin \& Tremblay, 1999). Alguns estudos afirmam que os comportamentos observados na infância - como o comportamento agressivo- estão relacionados às características de personalidade e ao estabelecimento de padrões de qualidade de adaptação social e psicológica apresentados durante todo o ciclo vital da pessoa (Ladd \& Burgees, 1999; Loeber \& Hay, 1997).

As primeiras interações da criança com o contexto no qual se desenvolvem aspectos relacionados a reciprocidade, vinculação e estabilidade já influenciam diretamente a qualidade da sua adaptação. Fora do contexto familiar, o contato da criança com seu grupo de iguais, como na escola, proporciona oportunidades de cooperação interpessoal, negociação e trocas que são essenciais à aprendizagem e ao desenvolvimento de interações saudáveis. Entretanto, interações pobres, conflituosas, infreqüentes ou ausentes geram sentimentos de rejeição e aumentam a probabilidade de prejuízos ao desenvolvimento, manifestos através de comportamentos desadaptados e desajustados (Bandura \& Walters, 1959; Coie \& Dodge, 1998; Ladd \& Burgees, 1999; Ladd \& Profilet, 1996; Rubin e cols., 1999; McWhiter, 1999; Nagin \& Tremblay, 1999; Pires, 1999).

Crianças agressivas expressam suas dificuldades de interação e adaptação através de seus comportamentos. A agressividade infantil é identificada no contato com o contexto no qual a criança se desenvolve e pode ser apontada como fator de risco para o seu ajustamento. Em casos extremos, o comportamento agressivo na infância pode resultar em casos de delinquiência, criminalidade, doença mental, evasão escolar e desempenho acadêmico pobre (Ladd \& Burgees, 1999; Ladd \& Profilet, 1996; Price \& Ladd, 1986; Rubin e cols., 1999).

O comportamento agressivo é definido como toda ação que causa ou implica danos ou prejuízos a alguém, e é expresso de forma confrontativa e/ou nãoconfrontativa. As formas confrontativas incluem atos diretos, físicos e verbais, como chutar, bater, morder, destruir objetos pessoais e de outros, machucar a si próprio, iniciar discussões, falar palavrões e xingamentos, fazer deboches, ameaças, ridicularizações e/ou provocações. As formas nãoconfrontativas incluem atos hostis indiretos, como atacar a reputação de outra criança, prejudicar o bom andamento das atividades, perturbar ambientes (incomodando, agitando-se) e provocar intrigas (Ladd \& Burgees, 1999; Loeber \& Hay, 1997). A agressividade assume estas formas de acordo com a direção e os objetivos para os quais se destina, diferenciando-se, por exemplo, de acordo com as relações de hierarquia entre a criança agressiva e o objeto de sua agressão (professores, colegas ou pais) e, também, de acordo com características inerentes ao próprio gênero (Coie \& Dodge, 1998).

A agressividade infantil direcionada aos(as) colegas de mesma idade e ao grupo de iguais é diferenciada daquela dirigida aos professores, aos pais e aos familiares. Esta diferença, certamente, está baseada na percepção da autoridade do outro e na posição hierárquica que ocupa. Quando direcionada aos (às) colegas e ao grupo de iguais, em geral manifesta-se sob formas confrontativas, através de conflitos, com agressões físicas, danos a objetos, e agressões verbais, com discussões, ameaças e ridicularizações. Quando direcionada aos professores, aos pais e/ou aos familiares, as formas de agressão são, em geral, não-confrontativas, envolvendo perturbação do ambiente escolar ou familiar (agitação motora, dispersão etc.), provocação de intrigas e dificuldades em engajar-se em jogos competitivos, em atividades cotidianas e na realização de tarefas (birras, manhas e oposição a ordens recebidas). (Bronfenbrenner \& Morris, 1998; Ladd \& Profilet, 1996).

A expressão da agressividade pode variar, também, de acordo com o gênero do protagonista da ação. Alguns estudos apontam que meninos são percebidos como mais agressivos que meninas (Coie \& Dodge, 1998; Cummings, Hollenbeck, Ianotti, Radke-Yarrow \& Zahn-Waxler, 1986). Entretanto, estes dados devem ser relativizados, considerando a forma como esta agressividade se manifesta. Enquanto os meninos parecem expressar, mais freqüentemente, seus comportamentos agressivos através de formas confrontativas (chutando, batendo, mordendo), as meninas tendem a demonstrar sua agressividade utilizando-se de formas não-confrontativas e agressões verbais (fazendo intrigas, atacando a reputação de outros etc.). Uma briga entre meninos é a expressão direta da agressividade física entre eles, sendo possível, na maioria das vezes, identificar aquele que iniciou a ação. Por outro lado, uma "fofoca" entre meninas pode passar muitas vezes desapercebida, especialmente no que diz respeito à sua origem. Razões biológicas, culturais e sociais são apontadas como responsáveis por estas diferenças. Biologicamente os meninos apresentam desenvolvimento distinto das meninas, e os estudos neurológicos evidenciam diferenças em termos de sinapses neuronais. Também existem evidências teóricas de que os meninos são biologicamente mais impulsivos e possuem maior tolerância à dor física que as meninas (Cummings e cols., 1986). No entanto, é 
evidente, nestas considerações, que a cultura e o contexto sócio-histórico exercem forte influência sobre os dados obtidos por estes estudos. É esperado culturalmente que os meninos sejam mais ativos, fortes, "brigões", e que as meninas sejam mais passivas e dóceis. Estes fatos, observados na realidade cotidiana, absolutamente não indicam que ambos os gêneros não possam expressar sua agressividade das mais variadas formas.

A agressão é uma das emoções humanas mais importantes, pois tem influência direta sobre o desenvolvimento pessoal e a vida em grupo. Crianças enfrentam mudanças de papel ou transições ecológicas entre os contextos nos quais se desenvolvem. Estes processos podem revelar vulnerabilidade $\mathrm{e}$ desajustamento de uma pessoa diante de situações naturais ao ciclo vital (nascimento de um irmão, entrada na escola, por exemplo), e que tendem a desadaptar a criança. A agressão, que pode emergir nestas ocasiões, tem a função de comunicação e está relacionada à adaptação. A criança adota o comportamento agressivo para buscar a readaptação ao contexto (Bronfenbrenner 1979/1996). A agressividade pode exprimir um pedido de ajuda, ao ser identificada como uma tentativa mal sucedida de adaptação. A criança, na tentativa de se adaptar ao mundo em que vive, escolhe, muitas vezes de forma ineficaz, os recursos que tem como disponíveis, gerando perturbação no ambiente e resultando em conseqüências negativas ao próprio desenvolvimento (Bronfenbrenner, 1979/1996; Bronfenbrenner \& Morris, 1998; Coie \& Dodge, 1998; Ladd \& Burgess, 1999; Loeber \& Hay, 1997).

A agressão expressa uma estratégia de coping, ou seja, um esforço comportamental consciente, cognitivo e/ou emocional, que a criança utiliza mediante situações percebidas como estressantes, a fim de aliviar a sensação de ansiedade gerada por estas (Lazarus \& Folkman, 1984). Uma estratégia agressiva pode assumir um caráter coercitivo-resistente, ou seja, a criança utiliza a agressividade para controlar pessoas e eventos (coerção) ou para resistir a imposições externas (resistência). Estratégias impositivas e autoritárias provocam problemas de relacionamento e sentimentos negativos de braveza e desgosto nos receptores da ação, levando a criança agressiva a ser rejeitada e a enfrentar conflitos com o grupo de iguais, com professores e/ou familiares (Ladd \& Burgees, 1999; Summerfeldt \& Endler, 1996; Tremblay, Herbert \& Piché, 1999).

A expressão da agressividade de crianças depende do momento individual e do contexto sócio-histórico no qual estão inseridas. Uma análise ecológica dos ambientes nos quais a criança transita demonstra como a agressão pode influenciar o seu desenvolvimento psicológico e as suas relações interpessoais (Bronfenbrenner, 1979/1996; Bronfenbrenner \& Morris, 1998). A escola é um exemplo de microssistema ecológico no qual a agressividade prejudica o desempenho acadêmico e o estabelecimento de relações saudáveis e próximas. Os "valentões", ou seja, aquelas crianças que, sistematicamente, confrontam e vitimizam seus colegas e professores, são identificados como crianças problemáticas e isoladas. Suas atitudes exigem atenção constante da escola para se evitar conflitos e para se manter o respeito estrito às regras, provocando a diminuição do investimento em sua formação acadêmica e intelectual. Crianças teimosas, que se opõem à realização das tarefas acadêmicas como uma forma hostil de reação ao que é esperado delas, são identificadas como "difíceis" e recebem menor investimento afetivo e acadêmico dos(as) professores(as) e colegas (Pelegrini \& Brooks, 1999).

Estudos sobre comportamento agressivo na infância possibilitam o planejamento de intervenções pontuais e preventivas. Para tal, no entanto, torna-se necessária a construção de instrumentos adequados, que possibilitem a execução de pesquisas e a avaliação destes comportamentos (Ladd \& Burgees, 1999; Ladd \& Profilet, 1996). Um dos métodos usuais de avaliação de comportamentos agressivos tem sido a observação em ambientes naturais. Este método tem se mostrado objetivo e revela poucas possibilidades de viés no foco de estudo. No entanto, exige procedimentos caros e requer disponibilidade de tempo e treinamento especializado de uma equipe de pesquisa. Paralelamente a isto, a coleta nítida e fidedigna dos dados pode ser atrapalhada por ruídos e por circulação e movimento de pessoas no ambiente, durante a observação. Por estas razões, outras estratégias metodológicas têm sido testadas para a obtenção de dados sobre os comportamentos agressivos de crianças. O relato de observadores, como por exemplo professores e colegas no ambiente escolar, tem propiciado a obtenção de informações sobre os comportamentos agressivos infantis de forma mais eficaz e fidedigna (Coie \& Dodge, 1988; Ladd \& Burgees, 1999; Ladd \& Profilet, 1996; Price \& Ladd, 1986). Relatos de professores apresentam vantagens, pois estes são capazes de traçar distinções objetivas entre os tipos de comportamento de seus alunos. Além disto, professores passam longos períodos de tempo com o seu grupo de estudantes, conhecendo cada um deles. Estes profissionais tornam-se, assim, mais hábeis para julgar aspectos qualitativos da interação 
infantil, como a expressão da capacidade de empatia, a timidez e a agressividade. A desvantagem deste método está, principalmente, em requerer a atenção do(a) professor(a) por um longo período, para responder às entrevistas e aos questionários sobre os seus alunos. Por isto, escalas estão sendo cada vez mais utilizadas, uma vez que são mais fáceis e rápidas de aplicar, além de ser um procedimento menos dispendioso (Coie \& Dodge, 1988; Ladd \& Profilet, 1996; Rubin e cols., 1999).

Vários instrumentos que visam obter informações sobre comportamentos infantis através da percepção dos professores têm sido apresentados pela literatura internacional (para uma revisão, ver Ladd \& Profilet, 1996). Estes instrumentos consistem, principalmente, em escalas construídas com base em aspectos sócio-emocionais, como agressividade, sociabilidade, liderança, atitudes, hiperatividade, impulsividade, ansiedade, medo e timidez (Rubin e cols., 1999). A Tabela 1 apresenta algumas referências de estudos norte-americanos que desenvolveram instrumentos para medir agressividade de crianças, entre outras variáveis. No Brasil, embora a área de estudos sobre desenvolvimento psicológico e Psicologia Escolar seja bastante produtiva, há carência de escalas de avaliação de comportamentos agressivos de crianças crianças (ver Conselho Federal de Psicologia, em http://www.pol.org.br). Baseado neste aspecto, este estudo visa descrever os procedimentos de construção e validação de conteúdo de uma escala de percepção, por professores, dos comportamentos agressivos de crianças na escola, apresentando, assim, uma nova possibilidade de instrumento de avaliação.

Tabela 1. Instrumentos norte-americanos elaborados para avaliar a percepção, por professores, dos comportamentos infantis (incluindo agressividade), e Referências.

\begin{tabular}{l|c|l}
\hline Instrumento & Referência & \multicolumn{1}{|c}{ Comportamentos } \\
\hline Child Behavior Profile & $\begin{array}{c}\text { Achenbach } \\
(1991)\end{array}$ & $\begin{array}{l}\text { Agressividade, retração, } \\
\text { distúrbios psicossomáticos, } \\
\text { problemas sociais, ansiedade, } \\
\text { depressão, problemas de } \\
\text { raciocínio e atenção, } \\
\text { comportamento delinqüente. }\end{array}$ \\
\hline $\begin{array}{l}\text { Preschool Behavior } \\
\text { Questionnaire }\end{array}$ & $\begin{array}{c}\text { Behar \& Stringfield } \\
(1974)\end{array}$ & $\begin{array}{l}\text { Ansiedade, medo, hostilidade, } \\
\text { agressividade, hiperatividade, } \\
\text { distração. }\end{array}$ \\
\hline $\begin{array}{l}\text { Teacher Assessment of } \\
\text { Social Behavior }\end{array}$ & $\begin{array}{c}\text { Cassidy \& Asher } \\
(1992)\end{array}$ & $\begin{array}{l}\text { Agressividade, timidez/retração, } \\
\text { comportamento pró-social e } \\
\text { desvios de conduta. }\end{array}$ \\
\hline Child Behavior Scale & $\begin{array}{c}\text { Ladd \& Profilet } \\
(1996)\end{array}$ & $\begin{array}{l}\text { Agressividade, comportamento } \\
\text { pró-social, comportamento anti- } \\
\text { social, exclusão pelos(as) } \\
\text { colegas, ansiedade/medo, } \\
\text { hiperatividade/distrabilidade }\end{array}$ \\
\hline
\end{tabular}

\section{PASSOS PARA CONSTRUÇÃO DA ESCALA}

Para a construção da escala sobre a expressão da agressividade infantil na escola foi necessário, inicialmente, revisar estudos existentes na literatura psicológica sobre os aspectos teóricos e metodológicos deste constructo. A partir deste procedimento, foram elaborados vinte e oito (28) itens que descrevem o comportamento agressivo de crianças. Para a redação de cada um dos itens foi adotada a forma afirmativa, de acordo com a Child Behavior Scale, elaborada por Ladd e Profilet (1996). A indicação de que professores seriam fontes confiáveis de informação sobre o comportamento agressivo de crianças implicou a elaboração de uma escala com itens dirigidos a eles sobre tais comportamentos.

A definição do constructo agressividade especifica comportamentos como chutar, bater, insultar, ridicularizar, estragar objetos (confrontativas) e provocar intrigas, perturbar a aula (nãoconfrontativas). Foram criados dezoito itens para avaliar agressão na forma confrontativa, sete para avaliar a forma não-confrontativa, um item para avaliar ambas as formas ("É uma criança agressiva", retirado da Child Behavior Scale, de Ladd \& Profilet, 1996) e dois itens para avaliar aspectos que indicam a presença de comportamentos desadaptados da criança na escola ["Seus (Suas) colegas reclamam de seu comportamento" e "O(a) professor(a) reclama de seu comportamento"].

Questões relativas à hierarquia entre os protagonistas da ação agressiva também foram anotadas durante a revisão da literatura (Coie \& Dodge, 1998). Tal informação exigiu a divisão dos itens criados em três categorias: agressividade direcionada aos professores $(\underline{\mathrm{n}}=9)$; agressividade direcionada aos(às) colegas $(\underline{n}=10)$, e agressividade em geral $(\underline{n}=9)$. A Tabela 2 apresenta os itens elaborados e suas classificações. A escala foi construída permitindo aos professores informar, em cada uma das afirmações, a percepção que têm de cada um de seus alunos. As respostas são marcadas em um contínuo de 1 (Discordo totalmente) a 5 (Concordo plenamente). As instruções para a aplicação da escala sugerem que seja administrada individualmente para cada professor(a) e que o nome completo da criança a ser avaliada seja mencionado claramente pelo pesquisador, evitando assim confusão entre os alunos de uma mesma sala de aula. O procedimento de avaliação para utilização da escala em pesquisas prevê o cálculo a partir da soma dos 
pontos marcados pelo(a) professor(a) em cada afirmativa.

Tabela 2. Itens da Escala de percepção, por professores, dos comportamentos agressivos de crianças na escola

\begin{tabular}{|c|c|c|c|c|c|}
\hline & \multicolumn{2}{|c|}{ Forma de expressão } & \multicolumn{3}{|c|}{ Questões hierárquicas } \\
\hline Itens & Confrontativas & \begin{tabular}{|c|c} 
Não \\
confrontativas
\end{tabular} & \begin{tabular}{|c|}
$\begin{array}{c}\text { Direcionada ao } \\
\text { professor(a) }\end{array}$ \\
\end{tabular} & $\begin{array}{c}\text { Direcionada } \\
\text { aos colegas }\end{array}$ & Geral \\
\hline $\begin{array}{l}\text { 1. É uma criança } \\
\text { agitada }\end{array}$ & & $\mathrm{X}$ & & & $\mathrm{X}$ \\
\hline $\begin{array}{l}\text { 2. Briga com os(as) } \\
\text { colegas }\end{array}$ & $\mathrm{X}$ & & & $\mathrm{X}$ & \\
\hline $\begin{array}{l}\text { 3. Tenta ridicularizar } \\
\text { o(a) professor(a) }\end{array}$ & $\mathrm{X}$ & & $\mathrm{x}$ & & \\
\hline $\begin{array}{l}\text { 4. Chora com } \\
\text { facilidade }\end{array}$ & & $\mathrm{X}$ & & & $\mathrm{X}$ \\
\hline $\begin{array}{l}\text { 5. Perturba o } \\
\text { andamento da aula } \\
\text { com sua conversa }\end{array}$ & & $\mathrm{X}$ & & & $X$ \\
\hline $\begin{array}{l}\text { 6. } \begin{array}{l}\text { Briga com o(a) } \\
\text { professor(a) }\end{array} \\
\end{array}$ & $\mathrm{X}$ & & $\mathrm{X}$ & & \\
\hline $\begin{array}{l}\text { 7. Chuta, bate, morde } \\
\text { os(as) colegas }\end{array}$ & $\mathrm{X}$ & & & $\mathrm{X}$ & \\
\hline $\begin{array}{l}\text { 8. Tem dificuldades } \\
\text { para trabalhar em } \\
\text { grupo } \\
\end{array}$ & & $X$ & & & $X$ \\
\hline $\begin{array}{l}\text { 9. Desafia o(a) } \\
\text { professor(a) }\end{array}$ & $\mathrm{X}$ & & $\mathrm{x}$ & & \\
\hline $\begin{array}{l}\text { 10. Tenta amedrontar, } \\
\text { intimidar o } \\
\text { professor(a) }\end{array}$ & $X$ & & $\mathrm{X}$ & & \\
\hline $\begin{array}{l}\text { 11. Estraga objetos } \\
\text { dos(as) colegas }\end{array}$ & $\mathrm{X}$ & & & $\mathrm{X}$ & \\
\hline $\begin{array}{l}\text { 12. Os colegas } \\
\text { reclamam de seu } \\
\text { comportamento }\end{array}$ & & & & $\mathrm{X}$ & \\
\hline $\begin{array}{l}\text { 13. } \mathrm{O}(\mathrm{A}) \text { professor(a) } \\
\text { reclama de seu } \\
\text { comportamento }\end{array}$ & & & $\mathrm{X}$ & & \\
\hline $\begin{array}{l}\text { 14. Costuma danificar } \\
\text { objetos do } \\
\text { ambiente escolar }\end{array}$ & $\mathrm{X}$ & & & & $\mathrm{X}$ \\
\hline $\begin{array}{l}\text { 15. Ameaça os(as) } \\
\text { colegas }\end{array}$ & $\mathrm{X}$ & & & $\mathrm{X}$ & \\
\hline 16. Fala palavrões & $\mathrm{X}$ & & & & $\mathrm{X}$ \\
\hline $\begin{array}{l}\text { 17. Discute com os(as) } \\
\text { colegas }\end{array}$ & $\mathrm{X}$ & & & $\mathrm{X}$ & \\
\hline $\begin{array}{l}\text { 18. Discute com o(a) } \\
\text { professor(a) }\end{array}$ & $\mathrm{X}$ & & $\mathrm{X}$ & & \\
\hline $\begin{array}{l}\text { 19. Ameaça o(a) } \\
\text { professor(a) }\end{array}$ & $\mathrm{X}$ & & $\mathrm{X}$ & & \\
\hline $\begin{array}{l}\text { 20. Amedronta e } \\
\text { intimida os(as) } \\
\text { colegas }\end{array}$ & $\mathrm{X}$ & & & $\mathrm{x}$ & \\
\hline $\begin{array}{l}\text { 21. Ridiculariza os(as) } \\
\text { colegas }\end{array}$ & $\mathrm{X}$ & & & $\mathrm{X}$ & \\
\hline $\begin{array}{l}\text { 22. Implica com os(as) } \\
\text { colegas e os (as) } \\
\text { provoca }\end{array}$ & $\mathrm{X}$ & & & $\mathrm{X}$ & \\
\hline $\begin{array}{l}\text { 23. Tem dificuldades } \\
\text { em jogos } \\
\text { competitivos }\end{array}$ & & $\mathrm{X}$ & & & $X$ \\
\hline $\begin{array}{l}\text { 24. Tenta agredir } \\
\text { fisicamente o(a) } \\
\text { professor(a) }\end{array}$ & $\mathrm{X}$ & & $\mathrm{X}$ & & \\
\hline $\begin{array}{l}\text { 25. Provoca intrigas } \\
\text { entre os(as) } \\
\text { colegas }\end{array}$ & & $\mathrm{x}$ & & $\mathrm{x}$ & \\
\hline $\begin{array}{l}\text { 26. É uma criança } \\
\text { dispersiva }\end{array}$ & & $\mathrm{X}$ & & & $\mathrm{X}$ \\
\hline $\begin{array}{l}\text { 27. Implica com o(a) } \\
\text { professor(a) e o(a) } \\
\text { provoca }\end{array}$ & $\mathrm{X}$ & & $\mathrm{X}$ & & \\
\hline $\begin{array}{l}\text { 28. É uma criança } \\
\text { agressiva }\end{array}$ & $\mathrm{x}$ & $\mathrm{X}$ & & & $\mathrm{X}$ \\
\hline
\end{tabular}

\section{PASSOS PARA A VALIDAÇÃO DE CONTEÚDO DA ESCALA}

Após a elaboração dos itens, iniciou-se a validação de conteúdo da Escala, através das opiniões de juízes sobre o instrumento construído. Este procedimento de avaliação consistiu em solicitar a vinte professores de Ensino Fundamental que trabalhassem com crianças na faixa etária de sete a doze anos, para que estes avaliassem cada um dos itens e opinassem se cada um deles poderia medir ou não comportamento agressivo de crianças na escola. Foi solicitado, também, a vinte psicólogos especialistas em desenvolvimento humano, com Mestrado ou Doutorado na área, que avaliassem cada um dos itens, utilizando o mesmo procedimento e a pertinência ao constructo que visavam representar.

Foi construído um instrumento contendo os vinte e oito itens da Escala, seguidos de duas questões cada um, ao qual os juízes deveriam responder. A primeira questão objetivava avaliar se o item media ou não a agressividade de crianças na escola, ou seja, a pertinência do item ao constructo teórico. Nela os juízes deveriam marcar zero (0) se o item "não mede" agressividade; um (1) se o item "mede parcialmente" agressividade; e, dois (2) se o item "mede" agressividade. A segunda questão almejava verificar se o comportamento expresso no item poderia ser considerado como dirigido ao(à) professor(a), aos(às) colegas ou ao âmbito geral. No final do instrumento foi acrescentada uma questão aberta, solicitando sugestões e comentários adicionais sobre cada um dos itens apresentados ou sobre a escala como um todo. Cada juiz recebeu a escala em seu local de trabalho e respondeu individualmente às questões descritas.

\section{RESULTADOS E DISCUSSÃO}

Após a coleta de dados com os juízes, foi realizada uma análise das freqüências e percentagens das respostas para cada um dos dados solicitados. As percentagens compartilhadas sobre a pertinência de cada item ao constructo teórico (ver Tabela 3) revelaram a concordância ou a discordância entre os juízes, servindo de critério de decisão sobre a permanência ou a exclusão do item da escala (Lind, 2000; National Council on Measurement in Education, 1999; Pasquali, 1999). Todos os itens considerados pelos juízes como ambíguos ou inadequados para medir a agressividade de crianças na escola foram excluídos. 
Tabela 3. Frequiências e percentagens da avaliação de pertinência de cada item e das categorias relativas às questões hierárquicas, pelos juízes $(\underline{n}=40)$.

\begin{tabular}{|c|c|c|c|c|c|c|}
\hline Item & $\begin{array}{l}\text { Categorias de } \\
\text { Avaliação }\end{array}$ & Frequiência & Percentual & $\begin{array}{l}\text { Categorias } \\
\text { Hierárquicas }\end{array}$ & Freqüência & Percentual \\
\hline \multirow{4}{*}{$\begin{array}{l}\text { 1. É uma criança } \\
\text { agitada }\end{array}$} & Não Mede & 18 & 45 & Professor(a) & 0 & 0 \\
\hline & \multirow[t]{2}{*}{$\begin{array}{l}\text { Mede } \\
\text { parcialmente }\end{array}$} & \multirow[t]{2}{*}{20} & \multirow[t]{2}{*}{50} & Colegas & 0 & 0 \\
\hline & & & & Geral & 33 & 82,5 \\
\hline & Mede & 2 & 5 & $\begin{array}{l}\text { Não } \\
\text { respondeu }\end{array}$ & 7 & 17,5 \\
\hline \multirow{5}{*}{$\begin{array}{l}\text { 2. Briga com } \\
\text { os(as) colegas }\end{array}$} & Não Mede & 1 & 2,5 & Professor(a) & 0 & 0 \\
\hline & \multirow[t]{2}{*}{$\begin{array}{l}\text { Mede } \\
\text { parcialmente }\end{array}$} & \multirow{2}{*}{9} & \multirow{2}{*}{22,5} & Colegas & 27 & 67,5 \\
\hline & & & & Geral & 12 & 30 \\
\hline & Mede & 29 & 72,5 & & & \\
\hline & $\begin{array}{l}\text { Não } \\
\text { respondeu }\end{array}$ & 1 & 2,5 & $\begin{array}{l}\text { Não } \\
\text { respondeu }\end{array}$ & 1 & 2,5 \\
\hline \multirow{5}{*}{$\begin{array}{l}\text { 3. Tenta } \\
\text { ridicularizar o(a) } \\
\text { professor(a) }\end{array}$} & Não Mede & 5 & 12,5 & Professor(a) & 29 & 72,5 \\
\hline & \multirow{2}{*}{$\begin{array}{l}\text { Mede } \\
\text { parcialmente }\end{array}$} & \multirow[t]{2}{*}{8} & \multirow[t]{2}{*}{20} & Colegas & 0 & 0 \\
\hline & & & & Geral & 10 & 25 \\
\hline & Mede & 26 & 65 & & & \\
\hline & $\begin{array}{l}\text { Não } \\
\text { respondeu }\end{array}$ & 1 & 2,5 & $\begin{array}{l}\text { Não } \\
\text { respondeu }\end{array}$ & 1 & 2,5 \\
\hline \multirow{4}{*}{$\begin{array}{l}\text { 4. Chora com } \\
\text { facilidade }\end{array}$} & Não Mede & 27 & 67,5 & Professor(a) & 0 & 67,5 \\
\hline & \multirow[t]{2}{*}{$\begin{array}{l}\text { Mede } \\
\text { parcialmente }\end{array}$} & \multirow[t]{2}{*}{12} & \multirow[t]{2}{*}{30} & Colegas & 0 & 0 \\
\hline & & & & Geral & 27 & 0 \\
\hline & Mede & 1 & 2,5 & $\begin{array}{l}\text { Não } \\
\text { respondeu }\end{array}$ & 13 & 32,5 \\
\hline $\begin{array}{l}\text { 5. Perturba o } \\
\text { andamento da }\end{array}$ & Não Mede & 20 & 50 & Professor(a) & 5 & 12,5 \\
\hline $\begin{array}{l}\text { aula com sua } \\
\text { conversa }\end{array}$ & $\begin{array}{l}\text { Mede } \\
\text { parcialmente }\end{array}$ & 15 & 37,5 & Colegas & 1 & 2,5 \\
\hline & & & & Geral & 27 & 67,5 \\
\hline & Mede & 5 & 12,5 & & & \\
\hline & & & & $\begin{array}{l}\text { Não } \\
\text { respondeu }\end{array}$ & 7 & 17,5 \\
\hline $\begin{array}{l}\text { 6. Briga com o(a) } \\
\text { professor(a) }\end{array}$ & Não Mede & 1 & 2,5 & Professor(a) & 31 & 77,5 \\
\hline & $\begin{array}{l}\text { Mede } \\
\text { parcialmente }\end{array}$ & 8 & 20 & Colegas & 0 & 0 \\
\hline & & & & Geral & 7 & 17,5 \\
\hline & Mede & 30 & 75 & & & \\
\hline & $\begin{array}{l}\text { Não } \\
\text { respondeu }\end{array}$ & 1 & 2,5 & $\begin{array}{l}\text { Não } \\
\text { respondeu }\end{array}$ & 2 & 5 \\
\hline $\begin{array}{l}\text { 7. Chuta, bate, } \\
\text { morde os(as) }\end{array}$ & Não Mede & 3 & 7,5 & Professor(a) & 0 & 0 \\
\hline colegas & $\begin{array}{l}\text { Mede } \\
\text { parcialmente }\end{array}$ & 1 & 2,5 & Colegas & 26 & 65 \\
\hline & Mede & 36 & 90 & & 12 & 30 \\
\hline & & & & $\begin{array}{l}\text { Não } \\
\text { respondeu }\end{array}$ & 2 & 5 \\
\hline $\begin{array}{l}\text { 8. Tem } \\
\text { dificuldades para }\end{array}$ & Não Mede & 18 & 45 & Professor(a) & 1 & 2,5 \\
\hline $\begin{array}{l}\text { trabalhar em } \\
\text { grupo }\end{array}$ & $\begin{array}{l}\text { Mede } \\
\text { parcialmente }\end{array}$ & 16 & 40 & Colegas & 9 & 22,5 \\
\hline & Mede & 5 & 125 & Geral & 19 & 47,5 \\
\hline & Nerce & J & & Não & 9 & 27,5 \\
\hline & $\begin{array}{l}\text { Não } \\
\text { respondeu }\end{array}$ & 1 & 2,5 & respondeu & & \\
\hline 9. Desafia o(a) & Não Mede & 4 & 10 & Professor(a) & 29 & 72,5 \\
\hline & $\begin{array}{l}\text { Mede } \\
\text { parcialmente }\end{array}$ & 21 & 52,5 & Colegas & 1 & 2,5 \\
\hline & & & & Geral & 8 & 20 \\
\hline & Mede & 14 & 35 & & & \\
\hline & $\begin{array}{l}\text { Não } \\
\text { respondeu }\end{array}$ & 1 & 2,5 & $\begin{array}{l}\text { Não } \\
\text { respondeu }\end{array}$ & 2 & 5 \\
\hline $\begin{array}{l}\text { 10. Tenta } \\
\text { amedrontar, }\end{array}$ & Não Mede & 2 & 5 & Professor(a) & 28 & 70 \\
\hline $\begin{array}{l}\text { intimidar o(a) } \\
\text { professor(a) }\end{array}$ & $\begin{array}{l}\text { Mede } \\
\text { parcialmente }\end{array}$ & 8 & 20 & Colegas & 1 & 2,5 \\
\hline & Mede & 30 & 75 & Geral & 11 & 27,5 \\
\hline
\end{tabular}

Tabela 3. Frequiências e percentagens da avaliação de pertinência de cada item e das categorias relativas às questões hierárquicas, pelos juízes ( $\underline{n}=40)$ (continuação).

\begin{tabular}{llcclccc}
\hline Item & $\begin{array}{l}\text { Categorias de } \\
\text { Avaliação }\end{array}$ & Frequiência & $\begin{array}{r}\text { Percentual Categorias } \\
\text { Hierárquicas }\end{array}$ & Frequiência & Percentual \\
\hline $\begin{array}{l}\text { 11. Estraga } \\
\text { objetos dos(as) }\end{array}$ & Não Mede & 1 & 2,5 & Professor(a) & 0 & 0 \\
colegas & $\begin{array}{l}\text { Mede } \\
\text { parcialmente }\end{array}$ & 8 & 20 & Colegas & 18 & 45 \\
& Mede & 31 & 77,5 & Geral & 21 & 52,5 \\
& & & & & &
\end{tabular}

\begin{tabular}{|c|c|c|c|c|c|c|}
\hline \multirow{4}{*}{$\begin{array}{l}\text { 12. Os colegas } \\
\text { reclamam de seu } \\
\text { comportamento }\end{array}$} & Não Mede & 6 & 15 & Professor(a) & 1 & 2,5 \\
\hline & $\begin{array}{l}\text { Mede } \\
\text { parcialmente }\end{array}$ & 21 & 52,5 & Colegas & 16 & 40 \\
\hline & & & & Geral & 20 & 50 \\
\hline & Mede & 13 & 2,5 & $\begin{array}{l}\text { Não } \\
\text { respondeu }\end{array}$ & 3 & 7,5 \\
\hline \multirow{4}{*}{$\begin{array}{l}\text { 13. O(a) } \\
\text { professor(a) } \\
\text { reclama de seu } \\
\text { comportamento }\end{array}$} & Não Mede & 6 & 15 & Professor(a) & 19 & 47,5 \\
\hline & $\begin{array}{l}\text { Mede } \\
\text { parcialmente }\end{array}$ & 22 & 55 & Colegas & 0 & 0 \\
\hline & Mede & 11 & 27.5 & Geral & 17 & 42,5 \\
\hline & $\begin{array}{l}\text { Não } \\
\text { respondeu }\end{array}$ & 1 & 2,5 & $\begin{array}{l}\text { Não } \\
\text { respondeu }\end{array}$ & 4 & 10 \\
\hline \multirow{4}{*}{$\begin{array}{l}\text { 14. Costuma } \\
\text { danificar objetos } \\
\text { do ambiente } \\
\text { escolar }\end{array}$} & Não Mede & 1 & 2,5 & Professor(a) & 0 & 0 \\
\hline & $\begin{array}{l}\text { Mede } \\
\text { parcialmente }\end{array}$ & 9 & 22,5 & Colegas & 0 & 0 \\
\hline & Mede & 30 & 75 & Geral & 39 & 97,5 \\
\hline & & & & $\begin{array}{l}\text { Não } \\
\text { respondeu }\end{array}$ & 1 & 2,5 \\
\hline \multirow{3}{*}{$\begin{array}{l}\text { 15. Ameaça } \\
\text { os(as) colegas }\end{array}$} & Não Mede & 1 & 2,5 & Professor(a) & 1 & 2,5 \\
\hline & $\begin{array}{l}\text { Mede } \\
\text { parcialmente }\end{array}$ & 4 & 10 & Colegas & 27 & 62,5 \\
\hline & Mede & 35 & 87,5 & Geral & 12 & 30 \\
\hline
\end{tabular}

\begin{tabular}{|c|c|c|c|c|c|c|}
\hline \multirow{4}{*}{$\begin{array}{l}\text { 16. Fala } \\
\text { palavrões }\end{array}$} & Não Mede & 5 & 12,5 & Professor(a) & 2 & 5 \\
\hline & $\begin{array}{l}\text { Mede } \\
\text { parcialmente }\end{array}$ & 23 & 57,5 & Colegas & 1 & 2,5 \\
\hline & & & & Geral & 35 & 87,5 \\
\hline & Mede & 12 & 30 & $\begin{array}{l}\text { Não } \\
\text { respondeu }\end{array}$ & 2 & 5 \\
\hline \multirow{4}{*}{$\begin{array}{l}\text { 17. Discute com } \\
\text { os(as) colegas }\end{array}$} & Não Mede & 4 & 10 & Professor(a) & 0 & 0 \\
\hline & $\begin{array}{l}\text { Mede } \\
\text { parcialmente }\end{array}$ & 25 & 62,5 & Colegas & 22 & 55 \\
\hline & & 11 & & Geral & 15 & 37,5 \\
\hline & & & & $\begin{array}{l}\text { Não } \\
\text { respondeu }\end{array}$ & 3 & 7,5 \\
\hline \multirow[t]{4}{*}{$\begin{array}{l}\text { 18. Discute com } \\
\text { o(a) professor(a) }\end{array}$} & Não Mede & 5 & 12,5 & Professor(a) & 26 & 65 \\
\hline & $\begin{array}{l}\text { Mede } \\
\text { parcialmente }\end{array}$ & 23 & 57,5 & Colegas & 1 & 2,5 \\
\hline & Mede & 11 & 27,5 & Geral & 10 & 25 \\
\hline & $\begin{array}{l}\text { Não } \\
\text { respondeu }\end{array}$ & 1 & 2,5 & $\begin{array}{l}\text { Não } \\
\text { respondeu }\end{array}$ & 3 & 7,5 \\
\hline \multirow{3}{*}{$\begin{array}{l}\text { 19. Ameaça o(a) } \\
\text { professor(a) }\end{array}$} & Não Mede & 1 & 2,5 & Professor(a) & 31 & 77,5 \\
\hline & $\begin{array}{l}\text { Mede } \\
\text { parcialmente }\end{array}$ & 6 & 15 & Colegas & 1 & 2,5 \\
\hline & Mede & 33 & 82,5 & Geral & 8 & 20 \\
\hline \multirow{3}{*}{$\begin{array}{l}\text { 20. Amedronta, } \\
\text { intimida os(as) } \\
\text { colegas }\end{array}$} & Não Mede & 1 & 2,5 & Professor(a) & 1 & 2,5 \\
\hline & $\begin{array}{l}\text { Mede } \\
\text { parcialmente }\end{array}$ & 4 & 10 & Colegas & 25 & 62,5 \\
\hline & Mede & 35 & 87,5 & Geral & 14 & 35 \\
\hline
\end{tabular}


Tabela 3. Freqüências e percentagens da avaliação de pertinência de cada item e das categorias relativas às questões hierárquicas, pelos juízes ( $\underline{n}=40)$ (continuação).

\begin{tabular}{|c|c|c|c|c|c|c|}
\hline Item & $\begin{array}{l}\text { Categorias de } \\
\text { Avaliação }\end{array}$ & Frequiência & Percentual & $\begin{array}{l}\text { Categorias } \\
\text { Hierárquicas }\end{array}$ & Frequiência & Percentual \\
\hline \multirow{3}{*}{$\begin{array}{l}\text { 21. Ridiculariza } \\
\text { os(as) colegas }\end{array}$} & Não Mede & 0 & 0 & Professor(a) & 0 & 0 \\
\hline & $\begin{array}{l}\text { Mede } \\
\text { parcialmente }\end{array}$ & 17 & 42,5 & \multirow[t]{2}{*}{ Colegas } & 29 & 72,5 \\
\hline & Mede & 23 & 57,5 & & 11 & 27,5 \\
\hline \multirow{3}{*}{$\begin{array}{l}\text { 22. Implica com } \\
\text { os(as) colegas e } \\
\text { os (as) provoca }\end{array}$} & Não Mede & 1 & 2,5 & Professor(a) & 0 & 0 \\
\hline & $\begin{array}{l}\text { Mede } \\
\text { parcialmente }\end{array}$ & 12 & 30 & \multirow{2}{*}{$\begin{array}{l}\text { Colegas } \\
\text { Geral }\end{array}$} & \multirow[t]{2}{*}{29} & \multirow{2}{*}{$\begin{array}{l}72,5 \\
27,5\end{array}$} \\
\hline & Mede & 27 & 67,5 & & & \\
\hline \multirow{4}{*}{$\begin{array}{l}23 \text { Tem } \\
\text { dificuldades em } \\
\text { jogos } \\
\text { competitivos }\end{array}$} & Não Mede & 15 & 37,5 & Professor(a) & 1 & 2,5 \\
\hline & $\begin{array}{l}\text { Mede } \\
\text { parcialmente }\end{array}$ & 16 & 40 & Colegas & 5 & 12,5 \\
\hline & \multirow{2}{*}{ Mede } & \multirow{2}{*}{9} & \multirow{2}{*}{22,5} & Geral & 25 & 62,5 \\
\hline & & & & $\begin{array}{l}\text { Não } \\
\text { respondeu }\end{array}$ & 9 & 22,5 \\
\hline \multirow{3}{*}{$\begin{array}{l}\text { 24. Tenta agredir } \\
\text { fisicamente o(a) } \\
\text { professor(a) }\end{array}$} & Não Mede & 1 & 2,5 & Professor(a) & 27 & 67,5 \\
\hline & $\begin{array}{l}\text { Mede } \\
\text { parcialmente }\end{array}$ & 2 & 5 & \multirow{2}{*}{$\begin{array}{l}\text { Colegas } \\
\text { Geral }\end{array}$} & \multirow{2}{*}{$\begin{array}{l}1 \\
12\end{array}$} & \multirow{2}{*}{$\begin{array}{l}2,5 \\
30\end{array}$} \\
\hline & Mede & 37 & 92,5 & & & \\
\hline \multirow{4}{*}{$\begin{array}{l}\text { 25. Provoca } \\
\text { intrigas entre } \\
\text { os(as) colegas }\end{array}$} & Não Mede & 2 & 5 & Professor(a) & 0 & 0 \\
\hline & $\begin{array}{l}\text { Mede } \\
\text { parcialmente }\end{array}$ & 17 & 42,5 & \multirow{2}{*}{$\begin{array}{l}\text { Colegas } \\
\text { Geral }\end{array}$} & 27 & 67,5 \\
\hline & \multirow{2}{*}{ Mede } & \multirow{2}{*}{21} & \multirow{2}{*}{52,5} & & 12 & 30 \\
\hline & & & & $\begin{array}{l}\text { Não } \\
\text { respondeu }\end{array}$ & 1 & 2,5 \\
\hline \multirow{4}{*}{$\begin{array}{l}\text { 26. É uma criança } \\
\text { dispersiva }\end{array}$} & Não Mede & 30 & 75 & Professor(a) & 4 & 10 \\
\hline & \multirow[t]{3}{*}{$\begin{array}{l}\text { Mede } \\
\text { parcialmente }\end{array}$} & 9 & 22,5 & Colegas & & 2,5 \\
\hline & & 1 & 2,5 & Geral & 25 & 62,5 \\
\hline & & & & $\begin{array}{l}\text { Não } \\
\text { respondeu }\end{array}$ & 10 & 25 \\
\hline $\begin{array}{l}\text { 27. Implica com } \\
\text { o(a) professor(a) }\end{array}$ & Não Mede & 3 & 7,5 & Professor(a) & 28 & 70 \\
\hline e o(a) provoca & $\begin{array}{l}\text { Mede } \\
\text { Parcialmente }\end{array}$ & 18 & 45 & Colegas & 0 & 0 \\
\hline & Mede & 19 & 47,5 & Geral & 11 & 27,5 \\
\hline & & & & $\begin{array}{l}\text { Não } \\
\text { respondeu }\end{array}$ & 1 & 2,5 \\
\hline 28. É uma criança & Não Mede & 3 & 7,5 & Professor(a) & 0 & 0 \\
\hline & $\begin{array}{l}\text { Mede } \\
\text { Parcialmente }\end{array}$ & 3 & 7,5 & Colegas & 0 & 0 \\
\hline & Mede & 33 & 82.5 & Geral & 37 & 92,5 \\
\hline & $\begin{array}{l}\text { Não } \\
\text { respondeu }\end{array}$ & 1 & 2,5 & $\begin{array}{l}\text { Não } \\
\text { respondeu }\end{array}$ & 3 & 7,5 \\
\hline
\end{tabular}

Apenas um item alcançou $75 \%$ ou mais de percentagem compartilhada, na categoria "Não mede", e foi eliminado ("É uma criança dispersiva"). Também foram eliminados os itens que alcançaram a percentagem de $75 \%$ ou mais, somando-se as categorias "Não mede" e "Mede parcialmente" ("É uma criança agitada", "Chora com facilidade", "Perturba o andamento da aula com sua conversa", "Tem dificuldades para trabalhar em grupo", "Tem dificuldades em jogos competitivos"). Os demais itens alcançaram $75 \%$ ou mais de percentagem na categoria
"Mede" ou somaram 75\% ou mais de percentagem nas categorias "Mede" e "Mede parcialmente" e foram, portanto, mantidos na versão final da Escala (ver Anexo A).

Com relação à direção da agressão, foi verificado que os juízes concordaram com a proposição da versão inicial. Apenas houve diferença em dois itens. Em "Os colegas reclamam de seu comportamento", os juízes avaliaram como agressividade dirigida tanto para os(as) colegas (40\%), como para o âmbito geral (50\%). No item "O(a) professor(a) reclama de seu comportamento", a agressividade foi avaliada como dirigida para o(a) professor(a) $(47,5 \%)$, mas também para o âmbito geral (42,5\%; ver Tabela 3$)$. Este resultado, na verdade, corrige a idéia inicial de que as reclamações feitas pelos(as) colegas e pelos(as) professores(as) expressam apenas comportamentos desadaptados dirigidos às suas pessoas e não outros comportamentos emitidos no contexto escolar, os quais são observados e provocam reclamações de todos.

Os comentários adicionais dos juízes, obtidos na última questão do instrumento, visavam principalmente solicitar esclarecimentos sobre alguns itens, ou sugerir outros. Alguns aspectos importantes foram apontados pelos juízes, especialmente com relação aos itens eliminados. Foi considerado que algumas afirmações, embora associadas à agressividade, relacionavam-se também à ansiedade ou a sintomas de distúrbios neurológicos e outros transtornos de comportamento. Foi indicada a eliminação destes itens, evitando comprometer-se a validade da Escala. Todas as sugestões de eliminação de itens foram acolhidas. Alguns juízes sugeriram a reformulação de alguns itens, como por exemplo: "Perturba o andamento da aula com sua conversa", especificado-se o tipo de conversa. Ao item "Tem dificuldades em jogos competitivos" foi sugerida a inclusão de uma justificativa para tal situação. Optouse pela eliminação destes dois itens, visto que não apresentavam clareza e objetividade na descrição do constructo agressividade em sua versão inicial, embora construídos a partir de definições apresentadas na literatura (Ladd \& Profilet, 1996).

Quatro novos itens foram sugeridos pelos juízes: "É uma criança arrogante e debochada", "Quando contrariada, nega-se a realizar tarefas", "Os pais dos(as) colegas reclamam do comportamento desta criança", e "É uma criança valentona". Estas sugestões foram julgadas como pertinentes e estes itens foram incluídos na versão final, uma vez que descreviam formas confrontativas ou não-confrontativas do comportamento e estavam presentes na literatura 
consultada (Ladd \& Profilet, 1996). Convém salientar que este foi um primeiro processo de validação ao qual a Escala foi submetida. É um procedimento válido, mas outras validações, como por exemplo validação de constructo, devem ser realizadas para este instrumento. Os itens novos acrescentados serão cuidadosamente observados pelos pesquisadores, na primeira aplicação da Escala, durante o Mestrado da primeira autora. Estes itens serão analisados e contrastados com os demais itens que visam medir o comportamento agressivo, a fim de se verificar sua confiabilidade.

Além destes procedimentos para a validação do conteúdo dos itens, foi também considerada importante a inclusão de alguns itens relativos a comportamentos positivos de crianças no contexto escolar. Tal procedimento, utilizado anteriormente por Ladd e Profilet (1996, p. 1012), visa "despistar" o participante da pesquisa acerca do constructo que a Escala avalia, evitando o viés no foco da investigação. Visa, ainda, possibilitar o bem-estar do participante, pois os itens sobre agressividade assumem um caráter negativo e podem suscitar sentimentos desagradáveis e mal estar. Itens positivos permitem, ainda, que os professores indiquem alguns comportamentos adaptados de seus alunos, evitando sentimentos de culpa ao avaliarem apenas aspectos agressivos de seus comportamentos (Ladd \& Profilet, 1996). Foram elaborados quinze (15) itens, incluídos após o processo de validação de conteúdo dos itens sobre agressividade, conforme apresentados na Tabela 4.

Tabela 4. Itens positivos incluídos na versão final da Escala de percepção, por professores, dos comportamentos agressivos de crianças na escola.

\begin{tabular}{ll}
\hline \multicolumn{1}{c}{ Itens neutros } \\
\hline 1. & Ouve o(a) professor(a) \\
2. & É confiável \\
3. & Reconhece quando seus colegas estão chateados \\
4. & Participa em sala de aula \\
5. & Ouve os(as) colegas \\
6. Ajuda os(as) colegas \\
7. Ajuda o(a) professor(a) \\
8. Tem amigos \\
9. É gentil com os(as) colegas \\
10. É gentil com o(a) professor(a) \\
11. É cooperativo \\
12. Preocupa-se com o que é certo e errado \\
13. Gosta de brincar em grupo \\
14. Gosta de trabalhar em grupo \\
15. Os(as) colegas demonstram gostar dele \\
\hline
\end{tabular}

Ao final do processo de validação de conteúdo obteve-se uma escala de 41 itens, sendo 22 afirmações de comportamentos agressivos, existentes na primeira versão da Escala, quatro (4) itens novos, acrescidos segundo a sugestão dos juízes durante a validação de conteúdo, e quinze (15) itens sobre comportamentos positivos. Estes itens foram distribuídos no instrumento de maneira aleatória, buscando mesclar itens positivos com aqueles que descreviam comportamentos agressivos. Este procedimento ocorreu para que o respondente não pudesse perceber que o constructo medido pela escala era agressividade das crianças, evitando viés no estudo. O procedimento de avaliação da escala para utilização em pesquisas prevê o cálculo de sete escores, a partir da soma dos pontos marcados pelo(a) professor(a) em cada afirmativa (que variam de 1 a 5): a) escore sobre formas confrontativas de expressão da agressividade percebidas pelo(a) professor(a); b) escore sobre formas não-confrontativas; c) escore sobre a agressão dirigida a professores; d) escore sobre a agressão dirigida aos(as) colegas; e) escore sobre a agressão dirigida ao âmbito geral; e) escore total f) escore dos itens positivos. Uma vez que as afirmativas das seis primeiras subescalas mencionadas descrevem comportamentos agressivos e que o contínuo de respostas vai de 1 (Discordo totalmente) a 5 (Concordo totalmente), quanto mais elevados forem os escores da criança, maiores evidências de que esta seja percebida como agressiva pelo(a) professor(a) naquela subescala. Os pontos obtidos na escala de itens positivos também devem ser somados, fornecendo informação sobre os comportamentos adequados da criança, percebidos pelo(a) professor(a). Na escala dos itens positivos, quanto maiores os escores da criança, maiores evidências de que esta seja percebida como manifestante do comportamento pró-social em sala de aula, na opinião da sua professora.

Novos estudos precisam ser realizados para avaliar a validade empírica ou preditiva da escala. A evidência de validade dos escores para cada uma das subescalas mencionadas anteriormente dependerá, com certeza, da elaboração de outros estudos, que avaliem e apoiem a adequação, o significado e a utilização das inferências específicas feitas por cada uma delas. A combinação de evidências de validade desta escala, e de suas subescalas, depende de estudos que obtenham dados de professores e permitam calcular resultados descritivos e a análise dos fatores que as compõem.

$\mathrm{O}$ estudo desenvolvido até o presente permite considerar a versão final da Escala de percepção, por professores, dos comportamentos agressivos de crianças na escola, apresentada no Anexo A, como um instrumento de mensuração adequado para utilização em pesquisas científicas. A base desta afirmação 
consiste na evidência de que o conteúdo dos itens e da Escala, elaborados a partir da literatura da área, foi considerado como válido, por um grupo de juízes, para avaliar comportamento agressivo de crianças na escola, segundo a percepção de seus professores. É importante salientar que esta Escala não deve ser utilizada, isoladamente, com o objetivo de obter dados sobre crianças para embasar aconselhamento terapêutico, psicopedagógico, educacional ou clínico. Também não deve ser utilizada como instrumento único para seleção, de qualquer tipo, das crianças ou dos professores ou para avaliação diagnóstica. Sua utilização mais indicada é como instrumento de pesquisa, e profissionais que a utilizam devem assumir um compromisso ético, que garanta a proteção e o respeito dos direitos dos eventuais respondentes da Escala, bem como das crianças avaliadas.

\section{REFERÊNCIAS BIBLIOGRÁFICAS}

Achenbach, T. M. (1991). Manual for teacher's report form and 1991 profile. Burlington: University of Vermont.

Bandura, A. \& Walters, R. H. (1959). Adolescent aggression: A study of the influence of child-training practices, and family interrelationships. New York: The Ronald Press Company.

Behar, L. \& Stringfield, S. (1974). A behavior rating scale for the preschool child. Developmental Psychology, 10, 601-610.

Bronfenbrenner, U. (1996). A ecologia do desenvolvimento humano: Experimentos naturais e planejados. Porto Alegre: Artes Médicas. (Originalmente publicado em 1979)

Bronfenbrenner, U. \& Morris, P. (1998). The ecology of developmental processes. Em W. Damon \& R. M. Lerner (Orgs.). Handbook of child psychology: Theoretical models of human development, (pp. 993-1027). New York: John Wiley \& Sons.

Cassidy, J. \& Asher, S. R. (1992). Loneliness and peer relations in young children. Child Developmental. 63, 350-365.

Coie, J. \& Dodge, K. (1998). Aggression and antisocial behavior. Em W. Damon \& N. Eisenberg (Orgs.). Handbook of child psychology: Social, emotional, and personality development, 3, (pp. 779-862). New York: John Wiley \& Sons.

Cummings, E. M., Hollenbeck, B., Ianotti, R., RadkeYarrow, M. \& Zahn-Waxler, C. (1986). Early organization of altruism and aggression: Developmental patterns and individual differences. Em C. Zahn-Waxler, E. M. Cummings \& R. Iannotti (Orgs.), Altruism and aggression: Biological and social origins, (pp. 165-188). New York: Cambridge University Press.
Conselho Federal de Psicologia (2000). Index-Psi Periódicos. Brasília. Disponível em <http://www.pol.org.br $>$. Acessado em 13 de fevereiro de 2000.

Ladd, G. \& Burgess, K. (1999). Charting the relationship trajectories of aggressive, withdrawn and aggressive/withdrawn children during early grade school. Child Development. 70, 910-929.

Ladd, G. W. \& Profilet, S. M. (1996). The child behavior scale: A teacher report measure of young children's aggressive, withdrawn, and prosocial behavior. Developmental Psychology. 32, 1008-1023.

Lazarus, R. S. \& Folkman, S. (1984). Stress, appraisal, and coping. New York: Springer.

Lind, G. (2000). O significado e medida da competência moral: Um modelo do duplo aspecto da competência moral. Psicologia: Reflexão e Crítica. 13, 399-416.

Loeber, F. \& Hay, D. (1997). Key issues in the developmental of aggression and violence from childhood to early adulthood. Annual Review of Psychological. 48, 371-410.

McWhirter, P. (1999). La violencia privada. American Psychologist. 54, 37-49.

Nagin, D. \& Tremblay, R. E. (1999). Trajectories of boy' s physical aggression, opposition, and hyperactivity on the path to physically violent and nonviolent juvenile delinquency. Child Development. 70, 1181-1196.

National Council on Measurement in Education (1999). Standards for educational and psychological testing. Washington, DC: American Psychological Association.

Pasquali, L. (1999). Instrumentos psicológicos: Manual prático de elaboração. Brasíla: LabPAM.

Pellegrini, A., Bartini, M. \& Brooks, F. (1999). School bullies, victims, and aggressive victims: Factors relating to group affiliation, and victimization in early adolescence. Journal of Educational Psychology. 91, 216-229.

Pires, J. (1999). Violência na infância: Aspectos clínicos. Em AMENCAR (Org.), Violência doméstica, (pp. 6170). Brasília: UNICEF.

Price, J. M. \& Ladd, G. W. (1986). Assessment of children's friendships: Implications for social competence and social adjustment. Advances in Behavioral Assessment of Children and Families. 2, 121149.

Rubin, K. H., Coplan, R. J., Nelson, L. J., Cheah, C. S. L. \& Lagace-Seguin, D. (1999). Peer relationships in childhood. Em M. H. Bornstein \& M. E. Lamb (Orgs.), Developmental psychology: An advanced textbook, (pp. 451-502). Mahwah, NJ: Lawrence Erlbaum.

Summerfeldt, L. \& Endler, N. (1996). Coping with emotion and psychopathology. Em M. Zeidner \& N. Endler (Orgs.), Handbook of coping: Theory, research, and applications (pp. 602-639). New York: John Wiley \& Sons. 
Tremblay, C., Hérbert, M. \& Piché, C. (1999). Coping strategies and social support as mediators of consequences in child sexual abuse victims. Child Abuse and Neglect. 23, 929-945.

\section{ANEXO A}

Escala de percepção, por professores, dos comportamentos agressivos de crianças na escola (Versão final).

\section{Caro(a) Professor(a):}

Marque, na escala abaixo, um número de 1 (Discordo totalmente) a 5 (Concordo plenamente), de acordo com a sua opinião sobre o(a) aluno(a)

Obrigado por sua colaboração neste estudo!

1) É uma criança cooperativa

Discordo totalmente _1_/_2_/_3_/_4_/5_/Concordo plenamente

2) Ouve o(a) professor(a)

Discordo totalmente _1_/_2_/_3_/_4_/_5_/ Concordo plenamente

3) Ouve os(as) colegas

Discordo totalmente _1_/_2_/_3_/_4_/_5_/ Concordo plenamente

4) É uma criança arrogante e debochada

Discordo totalmente _1_/_2__3_/_4_/5_/ Concordo plenamente

5) Os pais dos(as) colegas reclamam do comportamento desta criança com seus filhos

Discordo totalmente _1_/_2_/_3_/_4_/5_/Concordo plenamente

6) Participa em sala de aula

Discordo totalmente _1_/_2__3_/_4__5_/ Concordo plenamente

7) Briga com os(as) colegas

Discordo totalmente _1_/_2_/_3_/_4_/_5_/ Concordo plenamente

8) Tenta ridicularizar o(a) professor(a)

Discordo totalmente _1_/_2_/3_/_4_/5_/ Concordo plenamente

9) Quando contrariado, nega-se a realizar tarefas

Discordo totalmente _1_/_2_/_3_/_4_/_5_/ Concordo plenamente

10) Reconhece quando seus colegas estão chateados

Discordo totalmente _1_/_2_/_3_/_4_/5_/ Concordo plenamente
11) Briga com o(a) professor(a)

Discordo totalmente _1_/_2_/_3_/_4_/_5_/Concordo plenamente

12) Ajuda os(as) colegas

Discordo totalmente _1_/_2_/_3_/_4_/_5_/ Concordo plenamente

13) Ajuda o(a) professor(a)

Discordo totalmente _1_/_2_/_3_/_4_/_5_/Concordo plenamente

14) É uma criança considerada valentona

Discordo totalmente _1_/_2_/_3_/_4_/_5_/Concordo plenamente

15) Chuta, bate, morde os(as) colegas

Discordo totalmente _1_/_2_/_3_/_4_/_5_/Concordo plenamente

16) Tem amigos

Discordo totalmente _1_/_2_/_3_/_4_/_5_/Concordo plenamente

17) É uma criança agressiva

Discordo totalmente _1_/_2_/_3_/_4_/_5_/Concordo plenamente

18) Desafia o(a) professor(a)

Discordo totalmente _1_/_2_/3_/_4_/5_/ Concordo plenamente

19) Gosta de brincar em grupo

Discordo totalmente _1_/_2_/3_/_4_/5_/ Concordo plenamente

20) Tenta amedrontar, intimidar o(a) professor(a)

Discordo totalmente _1_/_2_/3_/_4_/5_/ Concordo plenamente

21) É gentil com os(as) colegas

Discordo totalmente _1_/2_/3_/_4__5_/ Concordo plenamente

22) Estraga objetos dos(as) colegas

Discordo totalmente _1_/_2_/3_/_4_/5_/Concordo plenamente

23) Seus colegas reclamam de seu comportamento Discordo totalmente _1_/_2_/3_/_4_/5_/ Concordo plenamente

24) $\mathrm{O}$ (a) professor(a) também reclama de seu comportamento

Discordo totalmente _1_/_2_/3_/_4_/5_/ Concordo plenamente

25) Costuma danificar objetos do ambiente escolar

Discordo totalmente _1_/2_/_3_/4_/5_/Concordo plenamente

26) É uma criança confiável 
Discordo totalmente _1_/_2_/3_/_4_/5_/ Concordo plenamente

27) Ameaça os(as) colegas

Discordo totalmente _1_/_2_/_3_/_4_/_5_/Concordo plenamente

28) Fala palavrões

Discordo totalmente _1_/_2_/_3_/4_/_5_/ Concordo plenamente

29) Gosta de trabalhar em grupo

Discordo totalmente _1_/_2_/3_/4_/_5_/ Concordo plenamente

30) Discute com os(as) colegas

Discordo totalmente _1_/_2_/_3_/_4_/_5_/ Concordo plenamente

31) Discute com o(a) professor(a)

Discordo totalmente _1_/_2_/3_/_4_/5_/ Concordo plenamente

32) Preocupa-se com o que é certo e errado

Discordo totalmente _1_/_2_/_3_/_4_/_5_/Concordo plenamente

33) Ameaça o(a) professor(a)

Discordo totalmente _1_/_2_/_3_/_4_/_5_/ Concordo plenamente

34) Amedronta, intimida os(as) colegas

Discordo totalmente _1_/_2_/3_/_4__5_/ Concordo plenamente
35) Ridiculariza os(as) colegas

Discordo totalmente _1_/_2_/3_/4_/_5_/ Concordo plenamente

36) Implica com os(as) colegas e os (as) provoca Discordo totalmente _1_/_2__3__4_/5_/ Concordo plenamente

37) É gentil com o(a) professor(a)

Discordo totalmente _1_/_2_/3_/_4_/5_/ Concordo plenamente

38) Os(as) colegas demonstram gostar dele

Discordo totalmente _1_/2_/_3_/4_/5_/ Concordo plenamente

39) Tenta agredir fisicamente o(a) professor(a)

Discordo totalmente _1_/_2_/3_/_4_/5_/ Concordo plenamente

40) Provoca intrigas entre os(as) colegas

Discordo totalmente_1_/2_/_3_/_4__5_/ Concordo plenamente

41) Implica com o(a) professor(a) e o (a) provoca

Discordo totalmente _1_/_2_/3_/_4_/5_/Concordo plenamente 